\title{
Antibacterial Activity of Roussin's Black Salt Against Multidrug Resistant Zoonotic Pathogens Isolated from Companion Animals
}

\author{
Elaine Meade ${ }^{1}$, Colin Fowley ${ }^{1}$, Micheal Savage ${ }^{2}$, Mark Anthony \\ Slattery ${ }^{3}$ and Mary Garvey ${ }^{1-3 *}$ \\ ${ }^{1}$ Department of Life Science, Sligo Institute of Technology, Sligo, Ireland \\ ${ }^{2}$ Lir Analytical LTD, Longford, Ireland \\ ${ }^{3}$ Mark Anthony Slattery MVB, Veterinary Practice, Manorhamilton, Leitrim, Ireland \\ *Corresponding Author: Mary Garvey, Department of Life Science, Sligo Institute \\ of Technology, Sligo, Ireland.
}

DOI: 10.31080/ASVS.2020.02.0046
Received: February 06, 2020

Published: February 13, 2020

(C) All rights are reserved by Mary Garvey., et al.

\begin{abstract}
Human and animal environments mutually transfer emerging and re-emerging pathogens by direct animal to human contact, cohabiting and direct contact to animal faeces resulting in the occurrence of zoonotic disease.. Antibiotic resistance contributes to prolonged and fatal cases of infection in animals and a is major risk factor for human morbidity with increasing prevalence globally. The aim of study is to establish the resistance profile of causative agents of disease in companion animals and to determine their sensitivity to Roussins black salt (RBS) as a potential antibacterial agent. Methods to determine antibiotic resistance include the Kirby disk diffusion assay and the inhibition of cell growth in the presence the test agent. All isolates showed alarmingly high levels of resistance to a variety of agents, where Pseudomonas aeruginosa was the most resistant pathogen, being only susceptible to one of the carbapenem antibiotics, doripenem. Furthermore, all Gram-negative canine isolates investigated demonstrated ESBL activity. Findings showed that test concentrations of RBS provided high levels of antibacterial activity against both Gram positive and ESBL producing Gram negative species of critical and high importance according the WHO priority pathogen list, where therapeutic antibiotics failed to do so. The findings suggest a potential of RBS to act as a potential antibacterial agent in the treatment of animal infectious disease where drug resistance is present, although further studies are warranted to elucidate its mode of action and animal biocompatibility profile. Keywords: Companion Animal; Multidrug Resistant; Pathogenic; Toxicity; Zoonosis
\end{abstract}

\section{Introduction}

Zoonotic disease transmitted from companion animals to humans represents a significant risk to public health safety, especially for neonates and immunocompromised persons. Domestic dogs are reservoirs for many pathogenic microbial species which may transmit via close contact to the animal, animal bedding and/ or excrement. Prophylactic and therapeutic approaches are used to decrease such transmission including limiting the presence of enteric pathogenic infections by feeding cooked meat to animals and implementing and adhering to vaccination programmes. Studies have shown that up to $60 \%$ of human infections are due to zoonotic transmission and are frequently mis-diagnosed due to a lack of awareness of the issue [1]. Pathogenic species of Escherichia coli (E. coli) are frequently associated with numerous human and animal disease states such as pneumonia, sepsis and infections of the urinary tract. Studies have identified the zoonotic transmission of pathogenic strains such as extended spectrum beta lactamase
(ESBL) producing and uropathogenic E. coli from animal to animal and from animal to human hosts [2]. Other pathogens commonly associated with zoonosis include serovars of Staphylococcus, Klebsiella, Enterococcus, Pseudomonas and Listeria [3], some of these species are listed on the World Health Organisation (WHO) priority pathogen list posing the greatest threat to human health. Furthermore, the presence of antimicrobial resistant (AMR) and multidrug resistant (MDR) bacterial infections in companion animals is of great concern. Various genetic similarities have been observed between MDR isolates from human infections, domestic animals and companion animal practices [4] including the human nosocomial pathogens carbapenemase-producing E. coli, MDR Klebsiella pneumoniae (K. pneumoniae) and P. aeruginosa [5]. All these species show potential for resistance to essentially all conventional antibiotics licensed for animal treatment. Moreover, genes encoding beta-lactamase and carbapenemase enzymes are carried on bacterial plasmids, typically in concurrence with other antimicrobial re- 
sistance mechanisms, allowing for horizontal gene transfer (HGT) of multidrug resistance between various bacterial species.

Animal hospitalization and prolonged antibiotic treatment particularly with cephalosporins and fluoroquinolones, represent significant risk factors associated with MDR bacterial infections and zoonotic transmission. Investigating the prevalence of antibiotic resistance and pathogenicity of veterinary bacterial isolates is extremely important from both veterinary and medical perspectives in order to ensure public health safety and conformity to the One Health approach. At present there is a lack of detail available on the activity of this compound again MDR zoonotic species. RBS a nitrosyl compound is investigated as an antibacterial agent demonstrating antimicrobial activity at micromolar concentrations. This study aimed to (i) identify causative agents of infection in diseased companion animals, (ii) determine the level of AMR and MDR of these species to a range of licensed antibiotic agents, and (iii) investigate a potential alternative option for treatment of systemic bacterial infection in companion animals. While the antibacterial activity of Roussin's Black Salt is well recognised, here we detail the efficacy of this compound against multidrug resistant zoonotic bacterial species of WHO critical and high importance.

\section{Methods}

Roussin black salt drug synthesis

Reagents and solvents for synthesis of RBS were purchased from Sigma Aldrich, Fisher and Apollo Scientific and were used as supplied. Drug synthesis of RBS was carried out as per the method of Meade., et al. 2019 [6]. RBS, being a polar compound, was dissolved in sterile phosphate buffered saline (Sigma Aldrich, Dublin, Ireland). Once completely dissolved with no precipitation evident, working concentrations of all test agents were then made by diluting the stocks in sterile $0.01 \mathrm{M}$ phosphate buffer, containing 0.0027 M KCL and $0.137 \mathrm{MNaCl}$ at a pH of 7.4 (PBS)(Sigma Aldrich, Dublin, Ireland).

\section{Bacterial isolation, identification, culture and maintenance}

Collected samples of infection or disease in the form of urine and blood material were provided by registered veterinary personnel in sterile containers (Cruinn Diagnostics, Dublin, Ireland). Liquid samples were immediately inoculated onto nutrient agar petri plates (Cruinn Diagnostics, Dublin, Ireland) and incubated at $37^{\circ} \mathrm{C}$ for 24 hours. Individual colonies were re-streaked for isolation and pure isolated colonies inoculated into nutrient broth for further biochemical characterization. Colonies were identified based on their morphological characteristics, biochemical profile and growth on selective agars, specifically CHROMagar ${ }^{\mathrm{TM}}$ MRSA, CHROMagar $^{\mathrm{TM}}$ Pseudomonas, CHROMagar ${ }^{\mathrm{TM}}$ VRE (CHROMagar, Paris), Harlequin $^{\text {TM }}$ E.coli/Coliform Medium, Harlequin ${ }^{\text {TM }}$ Listeria Chromogenic Agar, Baird Parker agar (LabM, Cruinn Diagnostics, Dublin, Ireland) and Klebsiella ChromoSelect agar (Sigma Aldrich, Dublin, Ireland). Identity was confirmed via colony polymerase chain reaction (PCR) as per Meade., et al. 2019 [7]. Following DNA extraction and amplification, clean-up and gene sequencing of PCR products was completed by Source Bioscience (Waterford, Ireland). Strains were stored long term in $20 \%$ glycerol at $-20^{\circ} \mathrm{C}$ and short term in nutrient broth at $5^{\circ} \mathrm{C}$ and identity confirmed via Gram stain and selective agars prior to each experimental set up.

Bacterial isolation, identification, culture and maintenance

Collected samples of infection or disease in the form of urine and blood material were provided by registered veterinary personnel in sterile containers (Cruinn Diagnostics, Dublin, Ireland). Liquid samples were immediately inoculated onto nutrient agar petri plates (Cruinn Diagnostics, Dublin, Ireland) and incubated at $37^{\circ} \mathrm{C}$ for 24 hours. Individual colonies were re-streaked for isolation and pure isolated colonies inoculated into nutrient broth for further biochemical characterization. Colonies were identified based on their morphological characteristics, biochemical profile and growth on selective agars, specifically CHROMagar ${ }^{\mathrm{TM}}$ MRSA, CHROMagar $^{\mathrm{TM}}$ Pseudomonas, CHROMagar ${ }^{\mathrm{TM}}$ VRE (CHROMagar, Paris),

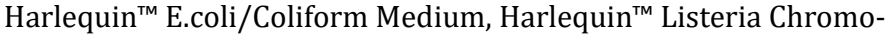
genic Agar, Baird Parker agar (LabM, Cruinn Diagnostics, Dublin, Ireland) and Klebsiella ChromoSelect agar (Sigma Aldrich, Dublin, Ireland). Identity was confirmed via colony polymerase chain reaction (PCR) as per Meade., et al. 2019 [7]. Following DNA extraction and amplification, clean-up and gene sequencing of PCR products was completed by Source Bioscience (Waterford, Ireland). Strains were stored long term in $20 \%$ glycerol at $-20^{\circ} \mathrm{C}$ and short term in nutrient broth at $5^{\circ} \mathrm{C}$ and identity confirmed via Gram stain and selective agars prior to each experimental set up.

\section{Antibiotic susceptibility testing}

Antibiotic resistance profiles were established using selective agars (CHROMagar ${ }^{\mathrm{TM}}$ ESBL CHROMagar $^{\mathrm{TM}}$ VRE) (Cruinn Diagnostic, Ireland) and a range of antibiotic susceptibility disks (ThermoFish- 
er Scientific, Ireland) guided by the European Committee for Antibiotic Susceptibility Testing (EUCAST) recommendations. ESBL detection and characterisation are recommended for public health and infection control purposes [8]. Specifically, colonies of an overnight bacterial culture suspended in sterile saline at a density of 0.5 McFarland turbidity (ca. $1 \times 10 \mathrm{e}^{8} \mathrm{cfu} / \mathrm{ml}$ ) were overlaid on to Mueller-Hinton $(\mathrm{MH})$ agar $(4 \mathrm{~mm})$ in $90 \mathrm{~mm}$ circular petri plate absent of surface moisture as per the EUCAST disk diffusion method [9]. An antibiotic inoculated disk was placed in the centre of the plate and incubated inverted for 18 hours at $35^{\circ} \mathrm{C}$. Zones of inhibition were measured in millimetre $(\mathrm{mm})$ where the absence of a zone of inhibition denotes complete resistance (R) in the organism, in this study. Susceptible species were then graded as susceptible (S) or as having intermediate (I) susceptibility based on the ability of the test drug to produce a zone diameter according to the EUCAST, 2019 zone diameters guide document [9]. A resistance profile was established in accordance with the WHO priority pathogen list for each species under investigation (Table 1) with critically important E. coli, P. aeruginosa and K. pneumoniae assessed for resistance to 3rd generation cephalosporins and a carbapenem amongst other drug classes. MRSA and VRE which are listed as high importance were assessed for resistance to vancomycin and quinolones amongst other therapeutics. Differentiating which drugs simply have an ' $\mathrm{S}$ ' and which ones have an ' $R$ ' is essential to clinicians, where susceptibility results guide treatment options. Quality control was achieved by use of American Type Culture Collection (ATCC) strains of E. coli, P. aeruginosa and Staphylococcus aureus (S. aureus) and K. pneumoniae adapted from table 1 of the EUCAST disk diffusion method (9) to ensure efficacy of the method used to determine resistance and susceptibility.

\begin{tabular}{|c|c|c|c|c|c|c|c|c|c|c|c|c|c|c|c|}
\hline \multirow{3}{*}{ 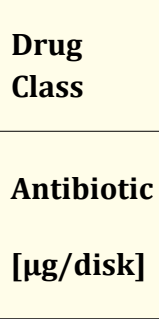 } & \multicolumn{2}{|c|}{$\begin{array}{l}\text { Aminoglyco- } \\
\text { side }\end{array}$} & \multirow{2}{*}{\begin{tabular}{|c|}
$\begin{array}{c}\text { Chlor- } \\
\text { amphen- } \\
\text { icol }\end{array}$ \\
$\begin{array}{c}\text { Chlor- } \\
\text { amphen- } \\
\text { icol }\end{array}$ \\
\end{tabular}} & \multirow{2}{*}{$\begin{array}{l}\begin{array}{c}\text { Macro- } \\
\text { lide }\end{array} \\
\text { Eryth- } \\
\text { romy- } \\
\text { cin }\end{array}$} & \multirow{2}{*}{$\begin{array}{c}\text { Penicil- } \\
\text { lin-like } \\
\text { Amoxi- } \\
\text { cillin/ } \\
\text { Clav }\end{array}$} & \multicolumn{2}{|c|}{ Cephalosporins } & \multirow{2}{*}{\begin{tabular}{|c|}
$\begin{array}{c}\text { Mono- } \\
\text { bactams }\end{array}$ \\
$\begin{array}{c}\text { Aztreo- } \\
\text { nam }\end{array}$ \\
\end{tabular}} & \multicolumn{2}{|c|}{ Carbapenems } & \multicolumn{2}{|c|}{ Quinolones } & \multirow{2}{*}{$\begin{array}{c}\begin{array}{c}\text { Poly- } \\
\text { myxin }\end{array} \\
\begin{array}{c}\text { Colis- } \\
\text { tin* }\end{array}\end{array}$} & \multicolumn{2}{|c|}{ Tetracycline } \\
\hline & $\begin{array}{l}\text { Strep- } \\
\text { tomy- } \\
\text { cin }\end{array}$ & $\begin{array}{l}\text { Kana- } \\
\text { mycin }\end{array}$ & & & & $\begin{array}{c}\text { Cefpo- } \\
\text { dox- } \\
\text { ime*^ }\end{array}$ & $\begin{array}{l}\text { Cefo- } \\
\text { taxi- } \\
\text { me*^ }\end{array}$ & & $\begin{array}{c}\text { Doripe- } \\
\text { nem* }\end{array}$ & $\begin{array}{c}\text { Merope- } \\
\text { nem* }^{*}\end{array}$ & $\begin{array}{l}\text { Levo- } \\
\text { floxa- } \\
\text { cin*^ }\end{array}$ & $\begin{array}{l}\text { Cipro- } \\
\text { floxa- } \\
\text { cin*^ }^{*}\end{array}$ & & $\begin{array}{c}\text { Doxy- } \\
\text { cy- } \\
\text { cline }\end{array}$ & $\begin{array}{l}\text { Tet- } \\
\text { racy- } \\
\text { cline }\end{array}$ \\
\hline & 10 & 30 & 30 & 15 & 20:10 & 10 & 5 & 30 & 10 & 10 & 5 & 5 & 10 & 30 & 10 \\
\hline $\begin{array}{l}\text { ESBL } \\
\text { E. coli* }\end{array}$ & 9 & 11 & $21(24)(I)$ & $\mathrm{R}$ & $\begin{array}{c}22(18- \\
24)\end{array}$ & $\mathrm{R}$ & $\mathrm{R}$ & $32(26)$ & $30(29)$ & $30(32)$ & $29(33)$ & $31(33)$ & 14 & 11 & 15 \\
\hline $\begin{array}{l}\text { ESBL K. } \\
\text { pneumo- } \\
\text { nia* }\end{array}$ & 11 & 13 & $\mathrm{R}$ & 9 & 14 & $\mathrm{R}$ & $\mathrm{R}$ & $38(26)$ & 31 & 30 & 9 & 12 & 12 & 11 & $\mathrm{R}$ \\
\hline $\begin{array}{l}\text { ESBL P. ae- } \\
\text { ruginosa* }\end{array}$ & $\mathrm{R}$ & 9 & $\mathrm{R}$ & $\mathrm{R}$ & $\mathrm{R}$ & $\mathrm{R}$ & $\mathrm{R}$ & $21(18)$ & $35(32)$ & $13(30)$ & $\mathrm{R}$ & $\mathrm{R}$ & 13 & 11 & $\mathrm{R}$ \\
\hline$M R S A^{\wedge}$ & $\mathrm{R}$ & 19 & $22(24)(\mathrm{I})$ & $15(26)$ & $11(22)$ & $\mathrm{R}$ & $\mathrm{R}$ & - & $\mathrm{R}$ & $\mathrm{R}$ & $28(S)$ & $29(S)$ & - & 11 & $\mathrm{R}$ \\
\hline$V R E^{\wedge}$ & $\mathrm{R}$ & 9 & 20 & 7 & 24 & 15 & $\mathrm{R}$ & - & $25(\mathrm{~S})$ & 12 & $\mathrm{R}$ & $\mathrm{R}$ & - & 30 & 28 \\
\hline $\begin{array}{l}\text { S. sapro- } \\
\text { phyticus }\end{array}$ & 8 & 22 & 23 & $\mathrm{R}$ & 10 & $\mathrm{R}$ & $\mathrm{R}$ & - & 16 & 15 & $29(S)$ & $25(S)$ & - & 16 & 10 \\
\hline $\begin{array}{l}\text { L. monocy- } \\
\text { togenes }\end{array}$ & 11 & 14 & 27 & 15 & 25 & 10 & $\mathrm{R}$ & - & 38 & 30 & 10 & 26 & - & 40 & 30 \\
\hline
\end{tabular}

Table 1: Antibiotic resistance profile of multi drug resistant zoonotic test species isolated from diseased companion animals. Numbers equate to zone of inhibition in millimetres.

Where R: Resistant; S: Susceptible and I: Intermediate Susceptibility to the Test Agent.

*WHO priority pathogen list critically important species and antibiotics.

${ }^{\wedge}$ WHO priority pathogen list highly important organism and antibiotics.

() zone of inhibition required by EUCAST to indicate susceptibility.

Citation: Mary Garvey., et al. "Antibacterial Activity of Roussin's Black Salt Against Multidrug Resistant Zoonotic Pathogens Isolated from Companion Animals". Acta Scientific Veterinary Sciences 2.3 (2020): 20-28. 


\section{Cell growth inhibition assay}

Microbial inhibition of growth and cell death assays were conducted for the test therapeutic agent both in the absence and presence of sheep blood/erythrocytes (Cruinn Diagnostic, Ireland) to stimulate practical conditions in the presence of an organic interfering agent. Bacterial test suspensions of each test species were prepared in nutrient broth and exposed to RBS at final concentrations of $10,20,100$, and $200 \mu \mathrm{M}$ as preliminary tests showed concentrations below $10 \mu \mathrm{M}$ to be ineffective. Bacterial inoculums containing $0.1 \%$ sheep erythrocytes were also prepared in nutrient broth and adjusted to reach above final concentrations. The resulting solutions were then seeded with a single colony of the respective test strain and incubated under rotary conditions (125rpm) at $37^{\circ} \mathrm{C}$ for 3 hours as per Hamilton-Brehm., et al. [10]. Controls contained nutrient broth with $0.1 \%$ blood and nutrient broth only. Subsequently, inoculums were serial diluted 10 -fold and $100 \mu \mathrm{l}$ of the diluted solution aseptically spread on nutrient agar plates in triplicate. All plates were incubated inverted for 24 hours at $37 \mathrm{oC}$. Surviving colonies were counted and reported as $\log 10 \mathrm{cfu} / \mathrm{ml}$ compared to an untreated control. In this manner, cell inhibition of growth of Gram-negative species was also determined for varying concentrations of aztreonam ranging from 0 to $30 \mathrm{mg} / \mathrm{L}$ as aztreonam is a monobactam antibiotic specifically used for the treatment of Gram-negative infections.

\section{RBS induced microbial cell death}

Cell death or viability of isolates was determined by measuring the rate of bacterial killing for each fixed concentration of drug under controlled conditions in a time-dependent manner. Bacterial suspensions containing $1 \times 10^{6} \mathrm{cfu} / \mathrm{ml}$ were prepared by incubating nutrient broth with a single colony of the test species for 6 hours at $37^{\circ} \mathrm{C} .10 \mathrm{ml}$ of the bacterial culture was then centrifuged at $10,000 \mathrm{rpm}$ for 10 minutes and resuspended in sterile PBS. Bacterial suspensions of known cell viability were then exposed to varying concentrations of RBS with control suspensions containing PBS without the presence of the test drug. As before, this was repeated in the presence of $0.1 \%$ blood to determine the inhibitory effects of organic interfering agents on the drug activity. Test suspensions were subsequently incubated under agitation $(120 \mathrm{rpm})$ at $37^{\circ} \mathrm{C}$. At set time intervals of 1,2 and 3 hours, $1 \mathrm{ml}$ of test suspension was 10 -fold serial diluted and $100 \mu \mathrm{l}$ aseptically spread on nutrient agar plates in triplicate. All plates were incubated inverted for
24 hours at $37^{\circ} \mathrm{C}$. Surviving colonies were counted and reported as $\log 10 \mathrm{cfu} / \mathrm{ml}$ compared to an untreated control.

\section{Results}

Table 1 displays the antibiogram of the seven bacterial canine isolates, where resistance to at least 3 antimicrobial agents was detected among all species making them multidrug resistant. The WHO critically important Gram-negative species, E. coli, K. pneumoniae and $P$. aeruginosa showed complete resistance to a variety of agents, including the aminoglycosides, tetracyclines, and marginal zones of inhibition for colistin with production of extended spectrum beta lactamase (ESBL) and subsequent resistance to 3rd generation cephalosporins (cefpodoxime and cefotaxime) evident. E. coli further displayed resistance to chloramphenicol, quinolones, carbapenems and amoxicillin clavulanate acid. Both K. pneumoniae and $\mathrm{P}$. aeruginosa (which possess intrinsic resistance to amoxicillin clavulanate), demonstrated clear resistance to the quinolones and chloramphenicol with $K$. pneumoniae demonstrating intermediate resistance to the cephalosporins and carbapenems. Indeed, $P$. $a e$ ruginosa showed resistance to virtually all antibiotic agents tested including meropenem, although susceptibility to doripenem was observed. Similarly, Gram-positive species displayed resistance to ampicillin, erythromycin, streptomycin, and the cephalosporins. All Gram-positive species produced minor zones $(<16 \mathrm{~mm})$ for vancomycin (a glycopeptide), where the Enterococcus species displayed complete resistance, further clarified by growth on CHROMagar ${ }^{\mathrm{TM}}$ VRE. The Staphylococcus species, MRSA (intrinsically resistant to the carbapenems) and Staphylococcus saprophyticus ( $S$. saprophyticus), both failed to meet the EUCAST target zone of $24 \mathrm{~mm}$ for chloramphenicol and $22 \mathrm{~mm}$ for amoxicillin clavulanate, with resistance to the tetracyclines also observed. In addition, MRSA displayed resistance to doripenem, though remained susceptible to meropenem while $S$. saprophyticus proved resistant to both carbapenem agents. Furthermore, susceptibility to the quinolones, levofloxacin and ciprofloxacin, were also evident for these species. Conversely, VRE exhibited resistance to the quinolone class, as well as to meropenem, albeit remained susceptible to doripenem and tetracycline. Listeria monocytogenes (L. monocytogenes) showed the lowest levels of resistance to all antibiotics compared to other isolated species, being susceptible to the tetracyclines, carbapenems, chloramphenicol and ciprofloxacin, though notably produced marginal zones of $13 \mathrm{~mm}$ and $10 \mathrm{~mm}$ for vancomycin and levofloxacin respectively. 
Figure 1 depicts the $\log _{10}$ cell growth inhibition of MDR bacterial test species following 3 hour incubation with varying concentrations $(10,20,100$ and $200 \mu \mathrm{M})$ of the test compound, RBS, both in the absence (a) and presence (b) of $0.1 \%$ sheep erythrocytes (which were used to determine inhibitory effects of organic material). As shown in figure 1a, varying levels of microbial inhibition were achieved for each test species, where Gram- positive species proved more sensitive. Indeed, a dose dependent increase in concentration of RBS stipulated a plateau effect for all Gram-positive species, with $100 \mu \mathrm{M}$ required for complete inhibition of growth for $S$. saprophyticus, MRSA, and VRE. The Gram-positive bacilli $L$. monocytogenes was significantly more sensitive where a concentration of $20 \mu \mathrm{M}$ provided complete inhibition. For Gram negative species however, findings revealed different results, where complete inhibition of cells was not obtained. While a plateauing response in inhibition was observed across the concentration gradient (at exceeding levels of $10 \mu \mathrm{M}$ ), the diminutive extent of this reduction was not comparable to that of the Gram-positive species. Notably K. pneumoniae was the most sensitive of the three Gramnegative test isolates, where a $5 \log _{10}$ inhibition was achieved at $200 \mu \mathrm{M}$. Both Gram negative species, E. coli and P. aeruginosa, showed similar findings to one another, where a maximum ca. $3 \log _{10}$ reduction was achieved for both species at a concentration of $200 \mu \mathrm{M}$ respectively. Conversely, in the presence of $0.1 \%$ blood (Figure 1b), all test isolates showed a decrease in sensitivity toward the RBS compound. In fact, little to no inhibition was achieved for the Gram-negative species, where test concentrations of 10,20 and $100 \mu \mathrm{M}$ had no effect. Interestingly, K. pneumoniae proved to be most resistant, where a concentration of $200 \mu \mathrm{M}$ showed slight inhibition (1.15 log), while a greater 2.32 and 2.65 $\log _{10}$ inhibition was achieved at this concentration for P. aeruginosa and $E$. coli respectively. Findings were similar for Gram-positive species, where complete inhibition of $S$. saprophyticus and MRSA were not achievable as seen in figure 1 a. Albeit, a ca. $4 \log _{10}$ and 5 $\log _{10}$ cell reduction was achieved for MRSA at corresponding concentrations of 100 and $200 \mu \mathrm{M}$. However, RBS did not prove as effective for $S$. saprophyticus, where a max $2 \log _{10}$ was achieved at $200 \mu \mathrm{M}$. VRE proved most sensitive in this scenario, followed by $L$. monocytogenes, where complete cell inhibition was achievable at the higher concentration of $200 \mu \mathrm{M}$. In addition, a notably decrease in $\log _{10}$ inhibition is observed across the concentration gradient for both these test species. Thus, the order of sensitivity (from highest to lowest) in the absence of blood is as follows; L. monocytogenes, VRE, MRSA, S. saprophyticus, K. pneumoniae, P. aeruginosa and E. coli. On the other hand, the chronological order in the presence of sheep erythrocytes (though not uniform at the lower concentrations $<20 \mu \mathrm{M}$ ) is as follows; VRE, L. monocytogenes, MRSA, S. saprophyticus, P. aeruginosa, E. coli and K. pneumoniae.
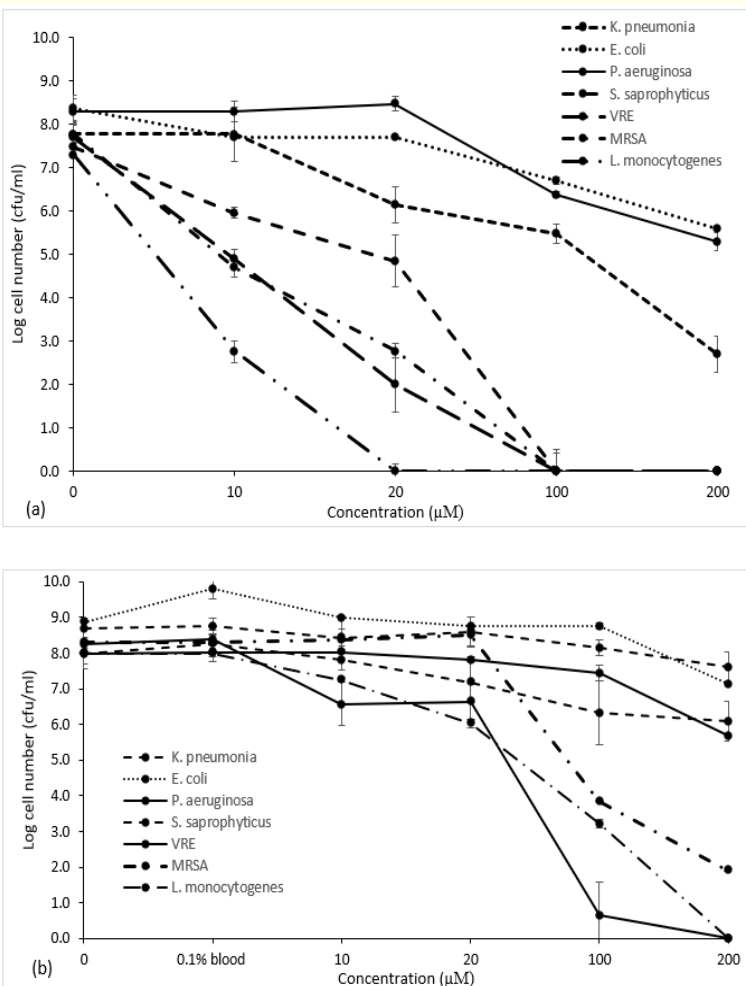

Figure 1: Log cell number (cfu/ml) of multidrug resistant gram negative and positive isolates following incubation with varying concentrations of RBS for 3 hours in the (a) absence and (b) presence of $0.1 \%$ blood (+/-S.D).

Figures 2 and 3 depict the $\log _{10}$ cell death of MDR species for each fixed concentration of drug over set time intervals of 1,2 and 3 hours in the absence and presence of $0.1 \%$ blood. Similar to the findings of figure $1, K$. pneumoniae was most sensitive to RBS in the absence of sheep erythrocytes, where a $1.3 \log _{10}$ cell death was 
achieved at the lower concentration of $10 \mu \mathrm{M}$, which followed a 0.4 $\log _{10}$ increase in cell death over the exposure time (Figure 2a). A concentration of $20 \mu \mathrm{M}$ provided a ca. $5 \log _{10}$ death at each hour for this species, with the higher concentrations, 100 and $200 \mu \mathrm{M}$, achieving a substantial $6 \log _{10}$ cell death. Contrastingly, the lower concentrations of 10 and $20 \mu \mathrm{M}$ showed to be less effective for both E. coli and P. aeruginosa, where $10 \mu \mathrm{M}$ had no effect on $E$. coli cells at any time point and provided a $1 \log _{10}$ cell death for P. aeruginosa at 2 and 3 hours. A concentration of $20 \mu \mathrm{M}$ did not produce the same rate of bacterial killing for E. coli, where a $3.7 \log _{10}$ cell death at 1 hour decreased by a ca. $1 \log _{10}$ every subsequent hour. Conversely, each hourly interval fashioned a $1 \log _{10}$ cell death for $P$. aeruginosa at this concentration, where a $1 \log _{10}$ cell death at 2 hours increased to a $2 \log _{10}$ death at 3 hours. At 1 hour a concentration of $100 \mu \mathrm{M}$ provided a $4 \log _{10}$ cell death for $E$. coli, which consecutively increased 1 log each hour to achieve a maximum 6 $\log _{10}$ cell death at 3 hours. Similarly, at this concentration P. aeruginosa follows an increase in $\log _{10}$ cell death, where bacterial cell death goes from $4 \log _{10}$ in the first hour to $6 \log _{10}$ in the following 2 and 3 hours. Furthermore, a concentration of $200 \mu \mathrm{M}$ provided a complete $6 \log _{10}$ cell death for both these Gram-negative species at all respective time points. However, similar to the inhibition assay, the presence of blood had a profound effect on the drugs ability to inactivate each test species. As seen in figure $3 \mathrm{a}$, a concentration of $10 \mu \mathrm{M}$ proved to have no effect on the Gram-negative species, where a further increase in concentration to $20 \mu \mathrm{M}$ only showed to have an effect on the P. aeruginosa isolate, achieving a $3 \log _{10}$ cell death in 3 hours. Indeed, the Gram-negative P. aeruginosa achieved the greatest level of cell death, where concentrations of 100 and $200 \mu \mathrm{M}$ provided a maximum $6 \log _{10}$ death each hour. Notably, $E$ coli and $K$. pneumoniae were again the most affected cells in the presence of blood, where a fixed $1 \log _{10}$ cell death was achieved at $100 \mu \mathrm{M}$ for $E$. coli at each time point. A greater level of bacterial killing was seen at this concentration for K. pneumonia, where a $2 \log _{10}$ cell death at 1 and 2 hours, increasing to $4 \log _{10}$ death at 3 hours. A further increase in $\log _{10}$ cell death was seen for both species at $200 \mu \mathrm{M}$ where a maximum $5 \log _{10}$ death was achieved in 3 hours. RBS provided higher levels of cell death for Gram-positive species both in the absence and presence of blood. As seen in figure $2 b$, MRSA and L. monocytogenes were the most susceptible isolates in the absence of blood, where a $5 \log _{10}$ cell death was observed at 1 hour for concentrations of 10 and $20 \mu \mathrm{M}$, which further increased to $6 \log _{10}$ cell death in the proceeding 2 and 3 hours. Moreover, a max $6 \log _{10}$ cell death was achieved at concentrations of 100 and $200 \mu \mathrm{M}$ for both test strains at all respective time points. Both VRE and $S$. saprophyticus isolates demonstrate complete cell death at 10 and $20 \mu \mathrm{M}$, with VRE reaching a max $6 \log _{10}$ cell death at both concentrations in 3 hours. Notably $S$. saprophyticus did not obtain a max cell death at $10 \mu \mathrm{M}$, where a $4.4 \log _{10}$ reduction is seen at 3 hours, however, it did manage to achieve this at $20 \mu \mathrm{M}$, where a $6 \log _{10}$ cell death is observed. Further concentrations of 100 and $200 \mu \mathrm{M}$ sustained a constant $6 \log _{10}$ cell death for both these species at each fixed time point. However, as seen from figure $3 b$, the presence of $0.1 \%$ blood likewise hindered the rate and level of cell death. Certainly, a concentration of $10 \mu \mathrm{M}$ did not provide the same loss in cell viability for Gram positive isolates (as prior observed in figure $2 \mathrm{~b}$ ). This was also evident at $20 \mu \mathrm{M}$, with an exception at 3 hours for VRE, where a marginal $2 \log _{10}$ death was achieved. A concentration of $100 \mu \mathrm{M}$ provided greater levels of cell death for Gram positive species, equating to a $4 \log _{10}$ cell reduction at 1 hour for VRE, L. monocytogenes and S. saprophyticus and a $6 \log _{10}$ reduction for MRSA. While a further dose increases to $200 \mu \mathrm{M}$ provided a 5.7 $\log _{10}$ cell death for $S$. saprophyticus and a maximum $6 \log _{10}$ death respectively for MRSA, VRE and L. monocytogenes. Findings show that in the presence of blood as interfering agent the level of RBS bacterial activity is greatly reduced but not completely diminished.
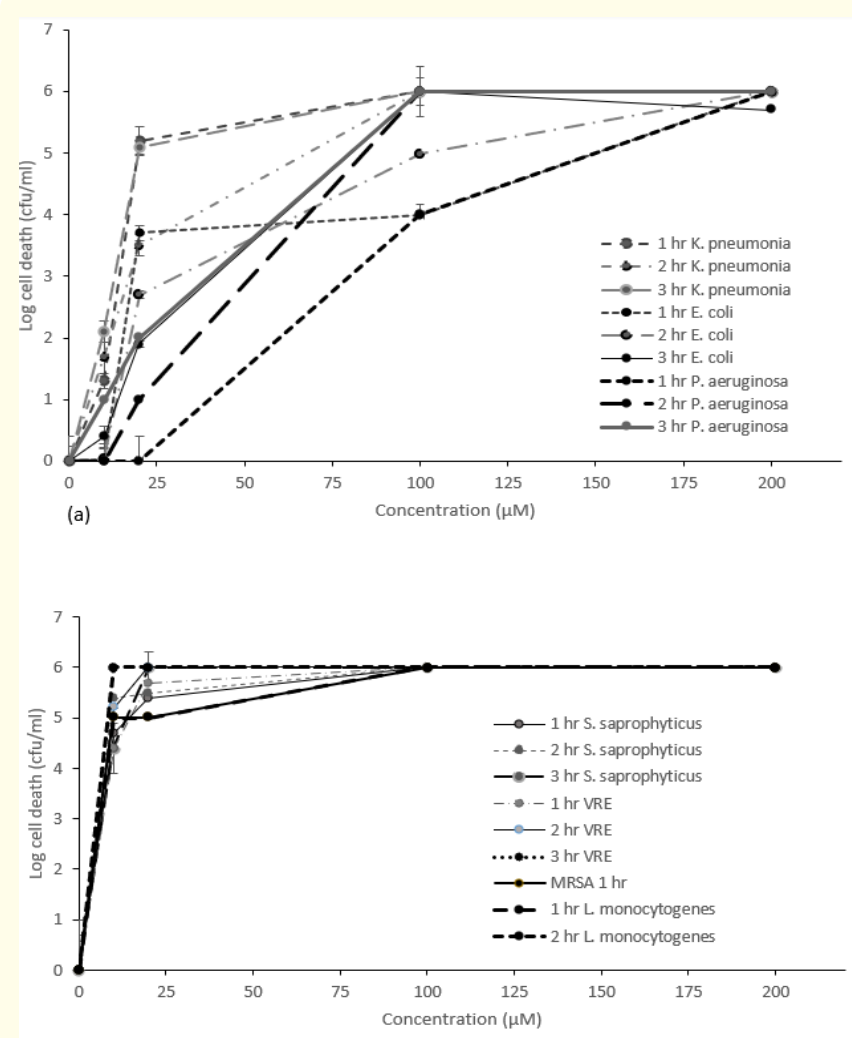

(b)

Figure 2: $\log _{10}$ cell death (cfu/ml) of multidrug resistant (a) gram negative isolates and (b) Gram positive isolates following exposure to varying concentrations of RBS for 3 hours (+/-S.D). 


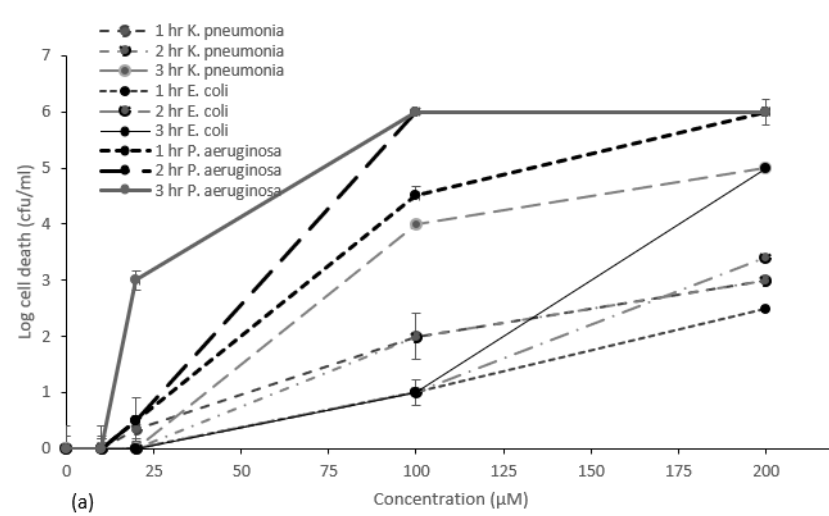

(a)

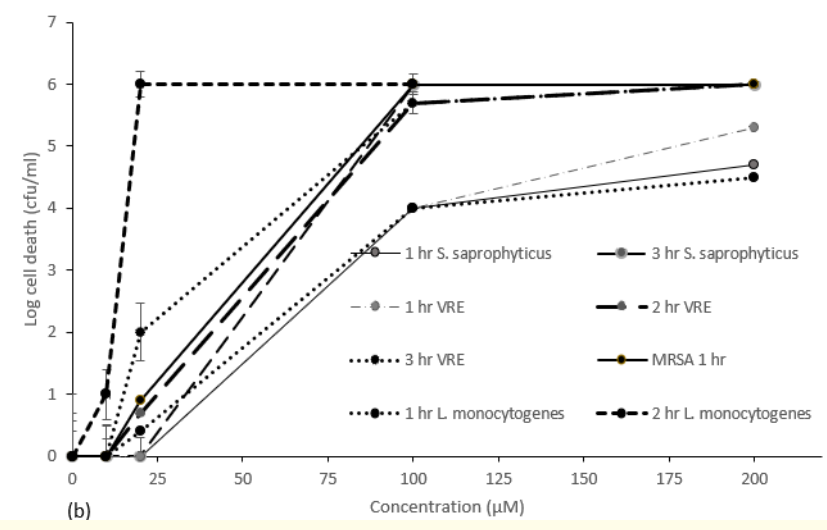

Figure 3: $\log _{10}$ cell death (cfu/ml) of multidrug resistant

(a) gram negative isolates and (b) Gram positive isolates following exposure to varying concentrations of RBS for 3 hours in the presence of $0.1 \%$ blood (+/-S.D).

Figure 4 depicts the $\log _{10}$ inhibition of ESBL producing MDR Gram-negative species, K. pneumonia, E. coli, and P. aeruginosa, following a 3-hour incubation period with varying concentrations of the antibiotic, aztreonam. Findings in this case indicate evident inhibitions in viable cell numbers across all concentrations $(3,7.5,15$ and $30 \mathrm{mg} / \mathrm{L}$ ), where $P$. aeruginosa proved the most resistant test species. Certainly, while a dose dependent increase in concentration induces a decrease in viable cell numbers for this organism, a $1.1 \log _{10}$ reduction was achieved at the greatest concentration of 30 $\mathrm{mg} /$ L. Test isolates, E. coli and K. pneumoniae showed similar findings at this concentration where 1.77 and $1.88 \log _{10}$ reduction are observed respectively. Notably, the level of inhibition for E. coli remained constant at concentrations of 15 and $30 \mathrm{mg} / \mathrm{L}$, where marginal findings of 0.47 and $0.79 \log _{10}$ are correspondingly evident at the lower concentrations of 3 and $7.5 \mathrm{mg} / \mathrm{L}$. MDR Klebsiella proved the most sensitive test species across all concentrations excluding $15 \mathrm{mg} / \mathrm{L}$, where $\log _{10}$ reduction of $0.57,1.57,1.57$ and 1.88 correlate to a dose increase in concentration.

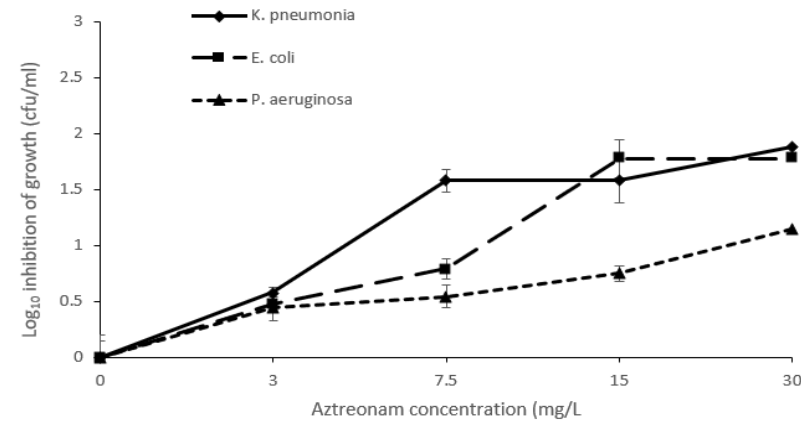

Figure 4: $\log _{10}$ inhibition of ESBL producing MDR Gram-negative test species exposed to the monobactam antibiotic Aztreonam (mg/L) for 3 hours (+/-S.D).

\section{Discussion}

RBS is a polar antimicrobial compound whose toxicity is potentially due to the 7 nitric oxide (NO) ligands present within the iron sulphur cluster [11] and is therefore a NO donor. This diatomic radical is thought to be responsible for the cytotoxic effects of RBS on several bacterial species. NO exerts both nitro active and oxidative stress within the bacterial cells ultimately leading to the disruption of the bacterial plasma cell membrane and subsequent cell lysis [10]. Interestingly, the study descrived herin demonstrated that (in the absence and presence of blood cells) Gram-positive bacteria were significantly more sensitive to RBS induced toxicity than Gram-negative. Indeed, both the Staphylococcus and Listeria species tested required a consequently smaller dose to provide complete cell inhibition. Given the differences in membrane structure between Gram-positive (outer peptidoglycan layer) and Gramnegative (outer membrane containing lipopolysaccharides) bacterial cells, this is something that needs further analysis to establish exact modes of RBS toxicity. Research findings also demonstrated a decreased sensitivity to RBS for both Gram-positive and Gramnegative bacteria in the presence of blood cells. Haemoglobin is the most abundant intraerythrocytic protein present in blood and it is well known that NO can strongly bind to this protein [11]. Since the bound NO has a decreased antibacterial activity, this may be the reason for the decreased sensitivity observed in the presence of blood cells. The order of sensitivity for the 7 bacterial species studied varied between the two experiments suggesting that some bacterial membranes may have a higher affinity for RBS. If this is true it is possible that the antibacterial potential of RBS may not be linked to the NO ligands present in the molecule but more so to a physical interaction of the compound with the cell membrane. Certainly, this theory was concluded by Hamilton-Brehm., et al. [10] during studies conducted on the hyper thermophilic Archaeon, 
Pyrococcus furiosus. This hypothesis also further supports the differences observed in sensitivity between Gram-positive and Gramnegative bacteria, where findings show, at least in the absence of blood, that a 2 -fold lower concentration $(100 \mu \mathrm{M})$ of RBS was sufficient in inhibiting complete bacterial growth of Gram-positive species when compared to Gram-negative species $(200 \mu \mathrm{M})$. Notably, it was seen for the Gram-positive L. monocytogenes that a 10-fold lower concentration of $20 \mu \mathrm{M}$ sufficed. Though interestingly the Enterobacterales species were consistently the most protected from RBS toxicity in the presence of blood, where inhibitory actions were significantly impaired at all concentrations, in addition to the rate of bacterial killing. Published studies demonstrate the antibacterial activity of RBS at much lower concentrations $(<5 \mu \mathrm{M})$ than described herein [10], but the use of MDR isolates in this study may account for the increased concentration needed to achieve similar levels of cell death. Notably, it can be said that the potential for RBS against these MDR species is promising. Aztreonam is a synthetic bactericidal drug that is selectively active against Gram-negative aerobic bacteria, having a high affinity for the protein-binding protein 3 (PBP-3) of cells [12]. The drug is therefore characteristically inactive against anaerobes and Gram-positive bacteria, with activity against Gram-negative species evident in this study (table 1). In this respect, the inhibitory effects of this drug were evident with all isolates displaying marginal $\log 10$ reductions across all tested concentrations. Like other antibiotics, aztreonam is a time- dependent killing agent, where the proportion of time at which its concentration is maintained above an organism's minimum inhibitory concentration (MIC) has been shown to be the predominant predictor of its efficiency. Moreover, this drug must be administered intravenously (IV) or intramuscular (IM) when used to treat systemic infections, as the absolute bioavailability after oral administration is extremely low at $<1 \%$ [13]. In vitro, the current EUCAST breakpoint for aztreonam for Enterobacterales is between 0.06-0.025 $\mathrm{mg} / \mathrm{L}$ while for $P$. aeruginosa the defined susceptibility breakpoint range is $2-8 \mathrm{mg} / \mathrm{L}$, where target MICs for both E. coli and P. aeruginosa are 0.125 and $4 \mathrm{mg} / \mathrm{L}$ respectively, using the broth microdilution method. No complete inhibitory concentration was observed for any isolated test species in respect to this drug, where max $\log 10$ reductions of $1.88,1.77$ and 1.14 at a concentration of 30 $\mathrm{mg} / \mathrm{L}$ were obtained for K. pneumoniae, E. coli and P. aeruginosa respectively. It is however worth mentioning that $P$. aeruginosa was the least susceptible of all test species to this drug. Additionally, P. aeruginosa remained the least effected pathogen in the presence of blood when treated with RBS. Additional findings for the aztreonam zones of inhibition presented in table 1, demonstrate that E. coli and K. pneumoniae did display susceptibility, exceeding the EUCAST zone diameter target of $26 \mathrm{~mm}$ for Enterobacterales while $P$. aeruginosa produced a $21 \mathrm{~mm}$ zone exceeding the $18 \mathrm{~mm}$ target zone. Undeniably, findings of table 1 demonstrate all canine isolates showed alarmingly high levels of resistance to a variety of agents, where $P$. aeruginosa was notably the most resistant pathogen, being only susceptible to one of the carbapenem antibiotics, doripenem and aztreonam. Furthermore, all Gram-negative canine isolates investigated demonstrated ESBL activity, where ESBL detection and characterisation is recommended by EUCAST for public health and infection control reasons. Resistance to cephalosporins and carbapenems in Gram-negative isolates is a prominent cause of concern, especially when mediated by transferable beta lactamase encoding genes, which dramatically limit treatment options. Certainly, rising resistance amongst canine species is becoming increasingly evident [14], though, it must be said there is a lack of studies presenting full antimicrobial profiles of companion animals isolates. Considering these experimental findings, it seems probable that the true potential of RBS as an antimicrobial agent will not be achieved until the mechanisms by which it interferes with bacterial cell growth are further explored and understood. Furthermore, biocompatibility studies are warranted on the toxicity profile of RBS on animal cell lines to establish a safe therapeutic dose, particularly as such high concentrations appear necessary to control MDR species. Potent antibacterial activity at sub cytotoxic concentrations is an ideal scenario, and this must be established in vitro. Studies have shown RBS to be toxic to human skin cell lines over a 24-hour exposure periods at concentrations above $1 \mu \mathrm{M}(15$ with an absence of studies detailing toxicity on cells derived from companion animals).

\section{Conclusion}

There is an increasing level of antibiotic resistance seen amongst pathogenic species infecting companion animals. As the relationship between animal infection, zoonotic transmission and human health becomes clear, there is a dire need to determine the full extent of the risks associated with multidrug resistance in canine incidence of disease. This study demonstrates the alarming level of resistance in Gram positive and negative isolates where ESBL production, resistance to aminoglycosides, tetracyclines and quinolones, was evident in E. coli, K. pneumoniae and P. aeruginosa species, amongst others. Similarly, Gram-positive species displayed resistance to ampicillin, erythromycin, streptomycin, and the cephalosporins with low susceptibility to vancomycin highlighting the risk to those co-habiting with companion animals.. The test agent Roussin's black salt provided significant levels of bacterial toxicity at the concentration range tested but this was reduced in the presence of erythrocytes. Further studies are warranted to establish the mode of action of RBS induced cell death on prokaryote species, 
where its ability to act as a standalone or combinational antibacterial agent should be verified.

\section{Conflict of Interest}

The authors declare there is no conflict of interest.

\section{Bibliography}

1. O'Neil J. "Zoonotic Infections From Common Household Pets". The Journal for Nurse Practitioners 14.5 (2018): 363-370.

2. Johnson JR., et al. "Sharing of Escherichia coli sequence type ST131 and other multidrug-resistant and urovirulent E. coli strains among dogs and cats within a household". Journal of Clinical Microbiology 47.11 (2009): 3721-3725.

3. Razzauti M., et al. "Zoonotic bacterial survey assessed by nextgeneration sequencing". Parasites and Vectors 7 (2014): 014.

4. Damborg P., et al. "Bacterial zoonoses transmitted by household pets: state-of-the-art and future perspectives for targeted research and policy actions". Journal of Comparative Pathology 155.1 (2016): S27-S40.

5. Müller S., et al. "Multidrug resistant Acinetobacter baumannii in veterinary medicine-emergence of an underestimated pathogen". Berl Munch Tierarztl Wochenschr 127 (2014): 435446.

6. Meade E., et al. "Assessment of novel therapeutic options for prolonged fungal infections in companion animals". Journal of Microbiology and Biotechnology 4.3 (2019a).

7. Meade E., et al. "Antibiotic resistant zoonotic pathogens of bovine mastitis and possible agents of foodborne disease". Cohesive Journal of Microbiology and Infectious disease 2.5 (2019b).

8. European Committee Antibiotic Suceptibility Testing, (EUCAST). EUCAST Clinical Breakpoint Tables v. 9.0, valid from 2019-01-01 (2019).

9. European Committee Antibiotic Susceptibility Testing, (EUCAST). Disk diffusion test documents (2019b).

10. Hamilton-Brehm SD., et al. "Antimicrobial activity of the ironsulfur nitroso compound Roussin's black salt [Fe4S3 (NO) 7] on the Hyperthermophilic Archaeon Pyrococcus furiosus". Applied and Environmental Microbiology 75.7 (2009): 18201825.

11. Gardner PR. "Hemoglobin: A Nitric-Oxide Dioxygenase”. Scientifica 34 (2014).
12. Li L and Li L. "Recent Advances in Multinuclear Metal Nitrosyl Complexes". Coordination Chemistry Reviews 306 (2016): 678700.

13. Janczyk A., et al. "NO-dependent phototoxicity of Roussin's black salt against cancer cells". Nitric Oxide 10(2004): 42-50.

14. Ramsey C and AP MacGowan. "A review of the pharmacokinetics and pharmacodynamics of aztreonam". Journal of Antimicrobial Chemotherapy 71.10 (2016): 2704-2712.

15. European Medicine Agency (EMA). "Reflection paper on the risk of antimicrobial resistance transfer from companion animals" (2015).

\section{Assets from publication with us}

- Prompt Acknowledgement after receiving the article

- Thorough Double blinded peer review

- Rapid Publication

- Issue of Publication Certificate

- High visibility of your Published work

Website: www.actascientific.com/

Submit Article: www.actascientific.com/submission.php

Email us: editor@actascientific.com

Contact us: +919182824667 